Article

\title{
Owners' Perceptions of Their Animal's Behavioural Response to the Loss of an Animal Companion
}

\author{
Jessica K. Walker ${ }^{1, *}$, Natalie K. Waran ${ }^{2}$ and Clive J. C. Phillips ${ }^{3}$ \\ 1 New Zealand Companion Animal Council, P.O. Box 43221, Auckland 2351, New Zealand \\ 2 Faculty of Education, Humanities and Health Science, Eastern Institute of Technology, Napier 4112, \\ New Zealand; nwaran@eit.ac.nz \\ 3 Centre for Animal Welfare and Ethics, School of Veterinary Sciences, University of Queensland, Gatton, \\ QLD 4343, Australia; cphillips@uq.edu.au \\ * Correspondence: manager@nzcac.org.nz; Tel.: +64-21-555825
}

Academic Editor: Marina von Keyserlingk

Received: 24 August 2016; Accepted: 27 October 2016; Published: 3 November 2016

Simple Summary: The loss of a companion animal is recognised as being associated with experiences of grief by the owner, but it is unclear how other animals in the household may be affected by such a loss. This paper investigates the behavioural responses of dogs and cats to the loss of an animal companion through owner-reported observations. There was consensus that behaviour changed as a result of loss including increased affectionate behaviour, territorial behaviour, and changes in food consumption and vocalisation.

\begin{abstract}
The loss of a companion animal is recognised as being associated with experiences of grief by the owner, but it is unclear how other animals in the household may be affected by such a loss. Our aim was to investigate companion animals' behavioural responses to the loss of a companion through owner-report. A questionnaire was distributed via, and advertised within, publications produced by the Royal Society for the Prevention of Cruelty to Animals (RSPCA) across Australia and New Zealand, and through a selection of veterinary clinics within New Zealand. A total of 279 viable surveys were returned pertaining to 159 dogs and 152 cats. The two most common classes of behavioural changes reported for both dogs and cats were affectionate behaviours ( $74 \%$ of dogs and $78 \%$ of cats) and territorial behaviours (60\% of dogs and $63 \%$ of cats). Both dogs and cats were reported to demand more attention from their owners and/or display affiliative behaviour, as well as spend time seeking out the deceased's favourite spot. Dogs were reported to reduce the volume $(35 \%)$ and speed $(31 \%)$ of food consumption and increase the amount of time spent sleeping $(34 \%)$. Cats were reported to increase the frequency $(43 \%)$ and volume $(32 \%)$ of vocalisations following the death of a companion. The median duration of reported behavioural changes in both species was less than 6 months. There was consensus that the behaviour of companion animals changed in response to the loss of an animal companion. These behavioural changes suggest the loss had an impact on the remaining animal.
\end{abstract}

Keywords: animal-animal bond; animal grief; cat; companion animal bond; dog

\section{Introduction}

Across Australia and New Zealand, the companion animal population comprises 36 million companion animals [1]. Internationally, both New Zealand and Australia have some of the highest cat and dog ownership rates with $44 \%$ of New Zealand households and $29 \%$ of Australian households owning a cat and $28 \%$ of New Zealand and $39 \%$ of Australian households owning a dog. This is a substantially greater number than the UK where $17 \%$ of households own a cat and $24 \%$ a dog 
and lower than the USA where $44 \%$ of households own a dog [1]. Owners of companion animals show strong emotional connections to their pets $[2,3]$ often considering them part of the family and showing affection, support and comfort in similar levels to that of a human family member [4-6]. Indeed, in some instances attachment to an animal companion may transcend relationships with other humans [5,7]. Inevitability, due to the vast number of companion animals within today's society, a large number of owners will experience separation from, or loss of, their companion animal and unsurprisingly such a loss is distressing, often causing the person significant grief and mourning $[6,8,9]$. The impact of the loss of a companion animal is well documented to result in an experience of grief that is not dissimilar to what one would experience as a result of the loss of a human to which they had a similar level of attachment $[7,10,11]$. Conversely, research investigating the impact companion animal loss has on any remaining animals within the household is not well documented.

The study of emotions in animals is essential to our understanding of their welfare, the advancement of which can lead to improvement in their quality of life. In recent years a number of methodologies have been developed and applied in an attempt to measure both positive and negative emotions in animals which may be relevant to the study of grief in animals including: neural homologies [12,13], behaviour and physiology assessment [14-16]; human judgment of subjective experience [17], and the measurement of cognitive appraisal of ambiguous stimuli which can signify overarching positive and negative emotional states $[18,19]$. Although the internal experiences of animals cannot be directly accessed, thereby rendering elusive any proof that animals experience a similar emotional experience of grief to humans, the methodologies described above have evidenced similarities in behavioural, physiological and neuroanatomical responses to separation [20,21], suggesting that some animals may have the capacity to experience negative feelings as a result of the loss of a conspecific [22]. From an evolutionary perspective grief may have evolved from a stress reaction in response to separation from companions, thereby acting to maintain group cohesion in social species [23].

For the purposes of this paper, grief is considered from a biological perspective as a response to separation, described by a bi-phase model of "active/passive" behavioural responses [24,25]. This biphasic modality is thought to function to increase the likelihood that separated, bonded animals will be reunited and is characterised by increased searching activity and vocalisations in the first phase and decreased activity and withdrawal from the environment (to conserve energy) in the second phase [24]. The response observed in farm animals following artificial weaning could be considered an example of this. In this situation farm animals attempt to reunite following the separation, and behaviours and physiological changes exhibited include: increased vocalisations, altered feeding patterns, increased locomotion, suspension of play, elevated corticosteroids, heart rate, core body temperature, and reduced immunocompetence [26-29]. Although there is no conclusive scientific evidence, the abrupt and permanent separation of offspring from their mothers in livestock management systems is increasingly being considered to be a significant emotional stressor for both the mother and the offspring [22]. Furthermore, anecdotal accounts of the emotional distress displayed as a result of the severance of mother-offspring bonds have been documented in wild baboons, elephants, chimpanzees and dolphins including; intense vocalisations and interaction with the deceased comprising of touching and carrying the body for prolonged periods of time before abandonment [30-33]. Field studies of elephants have documented strong vocal and behavioural reactions (including attempts to rouse the deceased) to the death of a family member $[30,34]$ and the attention that elephants give to bones and carcasses is suggested to be consistent with them comprehending and responding to the death of a conspecific [35]. The bi-phase model of "active/passive" behavioural responses to separation has been used to suggest that primates may experience grief in laboratory settings [36-38]. Primate mother-infant separation experiments, carried out primarily in the 1960's, demonstrated that infants (rhesus monkeys [39-41]; bonnet macaques [42]; and pig-tailed macaques [36,43,44]) exhibit an initial period, lasting from several hours to several days [45], of distress and agitation. This response is characterised by increased vocalisation, sleeplessness and activity, and followed by a period of reduced vocalisation, locomotory, 
exploratory and play activity that resembles depression. Further research has documented similarities between brain regions activated during mother-young separation in the guinea pig and those activated during the human experience of grief [21], which suggests that some animals experience emotional distress similar to the human experience of grief as a result of separation.

Although a great deal is known about the severance of mother-offspring bonds, little is known about the severance of peer bonds in companion animals [46]. Conspecific bonding in cats and dogs has not been extensively studied, but limited research has demonstrated that puppies have preferred play partners by six months of age [47] and are able to recognise their kin up to two years after separation [48], with social isolation of dogs documented to cause chronic stress [49]. Similarly, distress associated with the separation of littermates has been documented in kittens [50], suggesting that companion animals may form strong social bonds with peers. Indeed, some changes in the behaviour of both dogs and cats following the death of an animal companion have been anecdotally reported by companion animal owners [51].

While research on the severance of peer bonds in companion animals is sparse, there is a great deal written about owner-orientated separation anxiety. Dogs, suffering from owner-orientated separation anxiety, show functionally analogous behaviours to human infants in maintaining proximity and displaying stress-related behaviours after brief separation from their owner [52] followed by increased and prolonged displays of affection towards their owner upon reunion [53,54]. Separation from a human owner produces strong responses in over-attached dogs [55,56], which typically include destructive behaviour, escape attempts (to reunite with the owner), increased vocalisation and inappropriate elimination [53-55,57-60]. Dogs may also abstain from eating and drinking [61]. Behaviour symptomatic of separation anxiety in cats appears to parallel those seen in dogs, including inappropriate urination and defecation, increased vocalisation, destructiveness and psychogenic grooming [62]. It is possible that inappropriate urination and defecation, increased vocalisations and destructiveness could be considered to parallel the first phase of the bi-phasic definition of grief, whilst psychogenic grooming and abstaining from eating and drinking parallel the second phase.

The long-lasting relationship between owners and companion animals provides a unique source of inquiry regarding animal emotions [63]. Subjective ratings, observations and reports are a standard component of research within human psychology and include observations by clinicians, caregivers and peers as a substitute for self-report when self-report cannot be obtained [64], for example in the measurement of grief in individuals with intellectual disability, or young children $[65,66]$. In the case of animals, owners' assessments are the primary source of information regarding companion animal behaviour problems [67-69] with companion animal owners being increasingly utilised as a source of information about their animal's behaviour [63,70,71]. Indeed, owners have been demonstrated to provide meaningful and consistent reports about the behaviour of their animals [71] and recently, owners have been documented as being able to identify overt behavioural indicators of stress (e.g., trembling, crying or excessive barking) indicative of reduced welfare [72]. Consequently, companion animal owners are an ideal resource, in the first instance, to investigate behavioural changes in companion animals (through owner-perceived reporting) after the loss of an animal companion.

\section{Materials and Methods}

\subsection{Questionnaire Design}

The questionnaire was divided into two parts. The first section collected demographic data on the companion animal owner (including age range and gender), up to two deceased companion animals (deceased $<5$ years) and up to two remaining companion animals. Data obtained on the deceased animal(s) included species, breed, sex, age at death, date of death, cause of death and source of animal(s). Data obtained on the remaining animal(s) included species, breed, sex, age, whether the remaining animal saw the deceased animal's body and if so, how he/she reacted to it. Where owners reported on more than one deceased or remaining animal they were able to provide observed behavioural changes separately for each animal. Owners were free to include information on 
all companion animal species, however the paucity of information pertaining to species other than cats and dogs (rabbits, $n=3$; guinea pigs, $n=1$; alpacas, $n=1$, birds, $n=9$; rats, $n=4$; horses, $n=6$; and humans, $n=2$ ) meant that only information pertinent to dogs and cats was analysed. Based on owner descriptions of dog breed, both deceased and remaining, dogs were assigned to one of the seven New Zealand Kennel Club breed group categories (www.nzkc.org.nz/dogselect) or recorded as a crossbreed. Cats were categorised as either pedigree or domestic. The age of animals was categorised as juvenile ( $0-12$ months), adult ( $1-8$ years) or senior ( 8 years + ).

Section two of the questionnaire related to changes observed in the remaining animals' behaviour. Based on Schultz et al. [51], we utilised the following seven behavioural categories: feeding, sleeping, vocalisation, elimination, aggression, affection and territoriality. Under each of these behaviour categories owners were asked to indicate if, and how, particular behaviours changed in their remaining animal(s) by encircling the most relevant response, e.g., "increased", "decreased" or "change", "no change". Owners were also asked to estimate the duration of time that behaviour changes persisted. Specifically, using the above categories, owners were asked to comment on the amount and speed of food consumption and whether this affected their remaining animals health; the amount of time spent sleeping and whether the animal avoided his/her normal sleeping location; the amount of time spent vocalising and the volume of vocalisation; the frequency and location changes of elimination; aggression levels directed at animals or people in the household; whether the remaining animal(s) demanded more or less affection, displayed affiliative behaviour, which we termed "clingy/needy" or avoided contact, and whether remaining animals sought out or avoided the deceased animal's favourite spots, spent increased timing hiding or spent increased time "seeking higher ground".

\subsection{Questionnaire Distribution}

In New Zealand the questionnaire was distributed to 5500 potential respondents via the SPCA Auckland's "Animals Voice" magazine (Autumn issue 2010) and through 100 veterinary clinics throughout New Zealand, randomly selected from the veterinary practices listed on the New Zealand Veterinary Association Website (www.nzva.org.nz). Each copy of the aforementioned magazine included an inserted copy of the questionnaire. Each veterinary clinic was sent a research information sheet and a letter requesting that they advertise the questionnaire to their clients, along with 10 copies of the questionnaire. Seventeen clinics declined to participate. In order to ensure respondent anonymity, all questionnaires were returned to a postage paid Private Bag postal address.

In Australia advertisements for the survey were published in the RSPCA New South Wales quarterly magazine "Animals" (Summer issue 2010/2011) distributed to 6800 readers, the RSPCA Queensland's online newsletter "The Campaign Courier" (Winter issue 2010) distributed to 1800 readers and the RSPCA Victoria volunteer e-newsletter (Winter issue 2010) distributed to 800 readers. Interested readers were directed to an online version of the survey using the commercial software (SurveyMonkey 1999-2013). The advertisement gave a brief outline ( $<140$ words) of the research and a web link for the survey. Of the 6330 questionnaires distributed within New Zealand, 164 (2.6\%) were returned. Within Australia 142 (1.5\%) online questionnaire submissions were received. The nature of the questionnaire distribution in both New Zealand and Australia prevented us from determining the number of original questionnaires and advertisements that reached the nominated target audience (companion animal owners who had owned more than one companion animal with at least one of these animals having passed away in the previous five years).

All aspects of this research were approved by the Unitec Ethics and Research Committee, Auckland, New Zealand (2010-1044) and the Behavioural \& Social Sciences Ethical Review Committee, University of Queensland, Australia (2010000337).

\subsection{Statistical Analysis}

Data relevant to dogs and cats was analysed using Minitab version 16 (Minitab Inc., PA, USA). The data generally followed a non-parametric distribution pattern established using the Anderson 
Darling Test for normality, and hence non-parametric tests were engaged. Descriptive statistics were used to describe reported behavioural changes and their associated duration. Cross-tabulation with Chi-Squared $\left(\chi^{2}\right)$ test of association (or Fisher's Exact Test, where appropriate) was used to investigate associations between the species of deceased animal and the remaining animal. Significance was assumed if $p<0.05$.

\section{Results}

\subsection{Demographic Data}

Of the total 306 surveys received, 37 were incomplete and therefore discarded from analysis. The resulting sample of respondents $(n=279)$ comprised 254 females and 23 males, with $6 \%$ of respondents aged 18-25, 11\% 26-35, 21\% 36-45, 31\% 46-55, 19\% 56-65 and 13\% 66+ years. Seven hundred and seventy animals were represented, of which 356 were recently deceased (within the previous 5 years). Of the remaining (surviving) animals $(n=414), 75 \%(n=311)$ were identified by their owner as showing at least one behavioural change (159 dogs, 152 cats) subsequent to their companion passing away. Animal demographic data are summarised in Table 1.

Table 1. Demographic information on deceased and remaining companion dogs and cats reported by respondents to a self-selected questionnaire.

\begin{tabular}{|c|c|c|c|c|c|}
\hline & \multicolumn{2}{|c|}{ Dog } & & \multicolumn{2}{|c|}{ Cat } \\
\hline & $\begin{array}{l}\text { Deceased } n \\
\quad(\%)\end{array}$ & $\underset{(\%)}{\text { Remaining } n}$ & & $\begin{array}{l}\text { Deceased } n \\
\quad(\%)\end{array}$ & $\underset{(\%)}{\text { Remaining } n}$ \\
\hline \multicolumn{6}{|l|}{ Gender } \\
\hline Female & $117(59)$ & $102(52)$ & & $73(47)$ & $102(52)$ \\
\hline Male & $82(41)$ & $96(48)$ & & $83(53)$ & $94(48)$ \\
\hline Total & 199 & 198 & & 156 & 196 \\
\hline \multicolumn{6}{|l|}{ Age } \\
\hline Juvenile & $3(2)$ & $8(4)$ & & $11(7)$ & $11(6)$ \\
\hline Adult & $53(29)$ & $116(59)$ & & $33(22)$ & $89(46)$ \\
\hline Senior & $125(69)$ & $73(37)$ & & $109(71)$ & $95(49)$ \\
\hline Total & 181 & 197 & & 153 & 195 \\
\hline \multicolumn{6}{|l|}{ Breed } \\
\hline Toy & $9(5)$ & $11(6)$ & Pedigree & 31 & $46(24)$ \\
\hline Terrier & $25(13)$ & $36(19)$ & Domestic & 123 & $147(76)$ \\
\hline Gundog & $29(15)$ & $28(15)$ & Total & 154 & 193 \\
\hline Hound & $7(4)$ & $9(5)$ & & & \\
\hline Working & $39(20)$ & $30(16)$ & & & \\
\hline Utility & $19(10)$ & $18(6)$ & & & \\
\hline Non-Sporting & $13(7)$ & $11(6)$ & & & \\
\hline Crossbreed & $57(29)$ & $50(26)$ & & & \\
\hline Total & 198 & 193 & & & \\
\hline \multicolumn{6}{|l|}{ Cause of Death } \\
\hline Natural Causes & $52(27)$ & & & $28(18)$ & \\
\hline Euthanasia & $95(49)$ & & & $37(24)$ & \\
\hline Road Accident & $10(5)$ & & & $35(23)$ & \\
\hline Other & $37(19)$ & & & $52(34)$ & \\
\hline Total & 194 & & & 152 & \\
\hline \multicolumn{6}{|l|}{$\begin{array}{l}\text { Behaviour Directed } \\
\text { Towards Deceased }\end{array}$} \\
\hline Hissed or growled & & $0(0)$ & & & $4(7)$ \\
\hline Smelled and investigated & & $70(78)$ & & & $45(74)$ \\
\hline Showed no interest & & $12(13)$ & & & $11(18)$ \\
\hline Other & & $8(9)$ & & & $1(2)$ \\
\hline Total & & 90 & & & 61 \\
\hline
\end{tabular}


Table 2. Number (\%) of dogs and cats that displayed a behavioural change identified by their owners following the death of a companion animal.

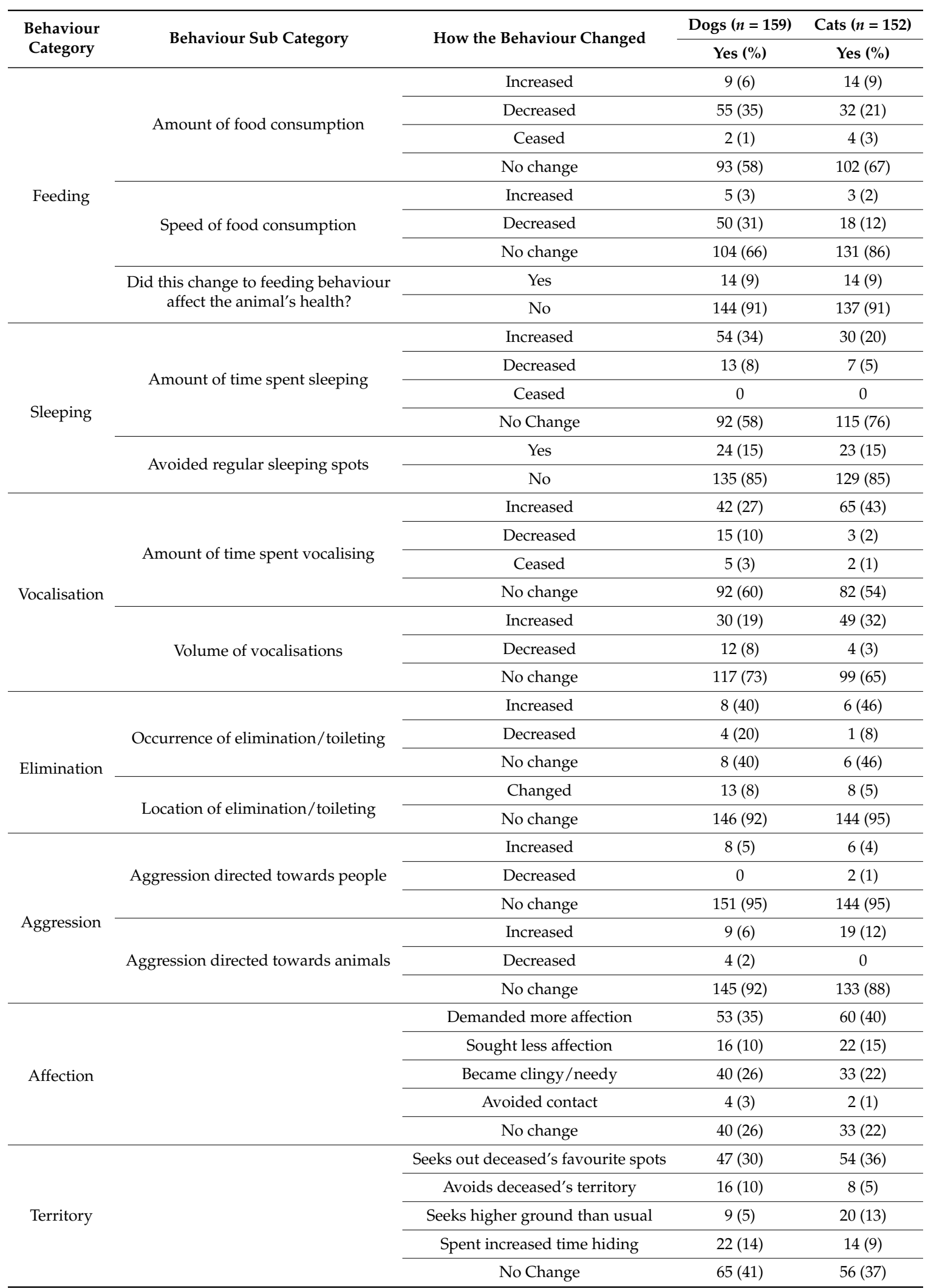




\subsection{Behavioural Changes}

Following the loss of an animal companion, owners reported a mean of $4.8 \pm 0.2$ behaviour changes in their dogs and $4.5 \pm 0.2$ in their cats.

Of the most commonly reported behavioural changes in dogs $\left(n_{\text {tot }}=153\right), 74 \%(n=113)$ were reported to display changes in affectionate behaviour, of which $35 \%(n=53)$ were described as more demanding of attention from their owner, $26 \%(n=40)$ were described as behaving in a clingy/needy manner. By contrast, $10 \%(n=16)$ were described as seeking less affection from their owner (Table 2). A total of $60 \%$ (94/159) of dogs were reported to display changes in territorial behaviour, of which $30 \%$ sought out the deceased's favourite spot (Table 2). Changes in sleep behaviour were reported for $42 \%$ $(67 / 159)$ of the dogs, with $34 \%$ displaying an increase in duration (Table 2). The amount and speed of food consumption was also reported to change in $42 \%(66 / 159)$ and $34 \%(55 / 159)$ of dogs respectively, with a decrease in volume observed in $35 \%$ and speed in $31 \%$ of the dogs (Table 2). Affectionate and sleep behaviour changes were reported to last for a median duration of 2-6 months, whilst changes in territorial and feeding behaviour were reported to last for a median duration of two months or less.

For cats, the most commonly reported behavioural changes included variation in affectionate behaviour $(78 \%$ of cats; $117 / 150)$, with $40 \%(n=60)$ of cats reported to have demanded more affection from their owner, whilst $22 \%(n=33)$ became increasingly clingy/needy and $15 \%(n=22)$ sought less affection (Table 2). Sixty-three percent of cats were reported to display a change in territorial behaviour (96/152), of which 36\% were reported to seek out the deceased animal's favourite spot (Table 2). Additionally, the frequency of vocalisations were reported to change in $46 \%(70 / 152)$ of cats with $43 \%$ displaying an increase, whilst in 35\% (53/152) of cats the volume of vocalisations was reported to change with $32 \%$ displaying an increased level (Table 2). For cats, the duration of changes in affectionate behaviour was reported to last for a median duration of between 2 and 6 months, whilst the median duration of changes in territorial and vocalisation behaviour was reported as 2 months or less.

\subsection{Species Influence}

Eighty two percent $(n=339)$ of the remaining animals that had lost a companion dog or cat. For remaining dogs, $79 \%(n=159)$ were reported to have lost a companion dog, whilst, $18 \%(n=36)$ had lost a companion cat. For remaining cats, $59 \%(n=125)$ had lost a companion cat and $9 \%(n=19)$ a companion dog. Whether the remaining animal's companion was of the same species was only found to have a statistical impact on one reported behaviour-the speed of food consumption. Remaining dogs who had lost a companion dog were more likely than those that had lost a companion cat to display a reduction in the speed with which they consumed food $\left(\chi^{2}=1.08, \mathrm{df}=1, p=0.0046\right)$. No significant difference was found between the duration of time for which behaviour changes occurred and whether the lost companion animal was the same, or different, to that of the remaining animal.

\subsection{Seeing the Deceased}

One hundred and fifty-eight remaining animals (dogs $58 \%$; cats $42 \%$ ) viewed their deceased companion's body. No difference was reported by owners between animals that saw, and those that did not see their companion's deceased body on the reported behavioural changes $\left(\chi^{2}=1.825, \mathrm{df}=1\right.$, $p=0.22)$. Upon viewing the deceased animal, the majority $(73 \% ; n=115)$ were reported to sniff and investigate the body of the dead companion.

\section{Discussion}

This study was a preliminary investigation into owner-perceived behavioural changes observed in companion animals following the loss of an animal companion. The most common behavioural change recognised and reported by owners was a change in the remaining animals' affectionate behaviour. The majority of both dogs $(74 \%)$ and cats $(78 \%)$ displayed a change, with $82 \%$ of these 
dogs and $97 \%$ of cats demanding more affection from, and/or, becoming more clingy/needy towards the owner. This behaviour appears to parallel two well reported components of owner-orientated separation anxiety in dogs; the anxious maintenance of close proximity displayed towards owners upon the presentation of departure cues, and the over exuberant affection directed at the owner upon their return [52-54] and could reflect an inner emotional experience of grief, anxiety, or distress. Alternatively this behavioural change could result from reduced competition for access to the owner, or a reflection of the absence of social facilitation previously caused by the presence of a conspecific.

Another key behavioural indicator of owner-orientated separation anxiety in both dogs and cats is increased vocalisations [53-55,58,59,62,73]. Owners of cats in the present study reported changes in both frequency $(46 \%)$ and volume (35\%) of vocalisations with $93 \%$ and $92 \%$, respectively, reported to increase, suggesting that the loss of a companion animal might be associated with the experience of anxiety. Aside from being a behaviour commonly associated with human-oriented separation anxiety, increased vocalisations following separation from conspecifics has also been documented in a range of farm animal species (goats, pigs, heifers, beef calves, lambs, dairy cows, horses [74-80]), a range of primate species [36,39-45] and elephants [30,81]. Increased vocalisations following the loss of an animal companion also parallel the first phase of the bi-phasic definition of grief which is characterised by increased searching activity and vocalisations [24].

Cats were also reported to show an increase in aggression directed towards other animals within the household. To our knowledge there is no literature on how cats behave as a result of the loss of a companion, aggressive behaviour is considered one of the most obvious signs of stress in cats [82]. Conversely, it is worth considering that an alternate explanation for the increased level of aggression reported in cats may have resulted from a change in hierarchical status resulting from the loss of a conspecific.

A large proportion of both dogs $(60 \%)$ and cats $(63 \%)$ were reported by their owners to display a change in territorial behaviour. More specifically, $50 \%$ of these dogs and $56 \%$ of these cats were described as seeking out the deceased animals' favourite spot. Schultz et al. [51] reported that $27 \%$ of dogs and $41 \%$ of cats, subsequent to the loss of a conspecific, sought out the deceased animals' favourite spot. Douglas-Hamilton et al. [30] have documented many elephant families travelling large distances to view the carcass of a deceased matriarch, and baboons have also been recorded searching for deceased infants when a troop re-enters an area where the infant died [33]. Consequently, this change in territorial behaviour may constitute the increased searching element of the first phase of the bi-phasic definition of grief. However, it is also possible that this behavioural change is the result of the remaining companion animal claiming this newly vacated territory as their own. Cats in particular are a very territorial species and the death of a companion animal could be perceived by the remaining animal as the removal of a resource competitor. Cats experiencing stress and decreased welfare tend to show increased hiding behaviour [83] and in the present study there were very low levels of this behaviour reported by owners $(9 \%)$. Further research is required to test out these alternate theories.

In the case of dogs, owners reported a change in the amount of food consumed (42\%) and speed with which the food was consumed (34\%) after the loss of a companion animal. Eighty three percent of these dogs displayed a reduction in the amount of food consumed, whilst $91 \%$ displayed a reduction in speed. This reduction in both quantity and speed may be a negative effect of the loss of a companion animal. Dogs suffering from owner-oriented separation anxiety often abstain from eating and drinking [61] and recently cognitive bias testing has demonstrated that dogs suffering from owner-oriented separation anxiety show a decreased latency to approach a potential food reward [56]. Similar changes in the eating habits of both cats and dogs were reported by Schultz et al. [51], with both species showing a reduction in consumption following the death of a conspecific ( $36 \%$ of dogs and $46 \%$ of cats). In the case of remaining dogs a reduction in the speed of food consumption was increasingly likely to occur if the deceased companion animal was a dog, which might reflect a stronger bond between these particular conspecifics. Alternately, it might be an artefact of the removal of a resource competitor rather than a stress response resulting from the loss of a companion. 
Dogs $(42 \%)$ were also reported to change their sleeping patterns. Changes in sleep patterns have been documented as a result of social isolation in rats [21], several species of primates [36,84] and farm animals [77], with a reduction in sleep being the most commonly reported change. In our study, $81 \%$ of the dogs reported to display a change in sleeping behaviour, were described as showing increasing levels of sleep which may parallel the second phase of the bi-phasic definition of grief which is characterised by decreased activity and withdrawal from the environment [24]. On the other hand increased sleep could be the result of less stimulation from a companion rather than an indicator of stress resulting from loss of an animal companion. To elucidate further on this finding, future research should obtain information regarding the duration of contact between the two companions and the nature of their cohabitation.

Our results show that witnessing the deceased animals' bodies did not have a significant impact on behaviour. Behavioural changes were observed regardless of whether the deceased's body was shown to the remaining animal. This might suggest that loss resulting from the removal of a companion animal from the household (e.g., sale or rehoming) could have a similar impact on behaviour, however further research is required to clarify this. Of the animals in the present study that were shown their companion's deceased body, 73\% sniffed and investigated the body. In other species, particularly primates and species considered to have high cognitive abilities (e.g., elephants and dolphins), behavioural interactions with conspecific carcasses have been reported. African elephants, for example, systematically investigate the bones and tusks of deceased elephants they encounter, visit the bones of relative elephants and display dramatic reactions towards dead and dying elephants [30,85]. Dolphins also show great interest in deceased individuals [31]. Japanese macaques have been documented to carry their deceased infants for up to a week before abandoning them [86]. Chimpanzees have been reported to carry their deceased infants for up to two months [87] before abandonment, and Cronin et al. [88] have described a behavioural response, including carrying and touching, of a chimpanzee mother towards her dead infant. Such interactive behaviour with the bodies of deceased animals has not just been reported as a result of the mother-offspring bond but also as a result of the severance of peer bonds. Brown [84] (p. 174) provides the following detailed behavioural response of an adult male chimpanzee to the loss of his mating partner. "After the death of the female ... the remaining one [male] made repeated attempts to arouse her, lifting up her head and hands, pushing her violently and rolling her over... The day following [removal of the body], he sat still most of the time and moaned continuously."

\section{Limitations}

Anthropomorphism may have played a role in owner descriptions of their animals' behavioural changes. This is an extension of the human ability to empathise with another individual, amplified to the extent that we attribute human emotions and feelings to another species without scientific evidence that they are capable of such feelings. Thus the owner reports of behavioural changes suggestive of grief presented here may be a reflection of the grief that the owner is experiencing or a behavioural change that has occurred as a result of the change in owner behaviour resulting from their own feelings of grief. A large number of studies have shown that companion animal owners describe human-dog interactions more anthropomorphically than non-owners [89-92]. Additionally, the "human substitute" function that companion animals play is likely to encourage owners to believe that their animals can experience more complex emotional responses than would be attributed by non-owners. Conversely, the close-lived nature of companion animal-human relationships allows owners to understand animals in a variety of ways which go beyond the ideas of instinctual behaviour responses and potentially allow owners to recognise the individual subjectivity of an animal [93].

Furthermore, we must acknowledge a likely bias in our respondent sample group. We asked respondents to nominate themselves to participate in this research and it is very likely the owners that responded did so because they saw a change in their animals' behaviour and because they remembered that change, whereas owners that did not see changes in behaviour may have been less likely to 
respond to our questionnaire. Given that our method of distribution was mainly through an animal welfare organisation, bias towards owners showing a greater motivation for animal behaviour and welfare issues may exist. Moreover, owners that believed companion animals capable of experiencing grief were likely more willing to respond to a questionnaire about animal grief. To address this limitation, future research could include a suite of questions about the owner's belief in animal mind [94]. Additionally, the 5 year limit following the occurrence of an animal passing was set to ensure respondents described behavioural changes following recent deaths. It must be acknowledged that as increasing time passes the accuracy of memory decreases. Future research should aim to collect data as events occur from a carefully selected target population, however, the delicate nature of the topic makes identifying and approaching the target audience something that requires careful consideration and planning.

Despite these limitations there was consensus among respondents that the behaviour of companion animals changed as a result of the loss of a companion animal. These behavioural changes appear to parallel behaviours observed during owner-orientated separation related anxiety. Increased knowledge of the common behavioural changes experienced by remaining animals raises the possibility that these behaviours can be addressed and discussed within the companion animal industry. Future research should attempt to disentangle the influencing variables through direct assessment of animal behaviour following the removal of an animal companion, though the sensitive nature of the subject may constrain participation of companion animal owners.

\section{Conclusions}

Companion animal owners reported behavioural changes in their animals following the loss of a companion. Further analysis of behavioural changes, independent of owner interpretation, is required to establish whether these behavioural changes are indeed a reflection of loss, result from a reduction in competition for resources or are a consequence of change in owner behaviour resulting from either their own feelings of grief or concern that their companion animal is grieving.

Acknowledgments: The authors would like to thank SPCA Auckland for the distribution of the questionnaire with their quarterly magazine, Animals Voice, the 83 veterinary clinics throughout New Zealand, RSPCA Victoria, RSPCA Queensland and RSPCA New South Wales for distributing the questionnaire and the Morris Animal Foundation for financially supporting this research through a Veterinary Student Scholar Project Award. Finally, the authors would like to thank respondents for their time.

Author Contributions: Jessica K. Walker, Clive J. C. Phillips and Natalie K. Waran conceived and designed the survey. Jessica K. Walker collected and analysed the data and wrote the paper. Clive J. C. Phillips assisted with data analysis and extensive editing of the paper. Natalie K. Waran edited the paper.

Conflicts of Interest: This research was funded by the Morris Animal Foundation (Veterinary Student Scholar Project Award) who played no role in the study design nor in the collection, analysis and interpretation of data, nor in the decision to submit the manuscript for publication. None of the authors has any financial or personal relationships that could inappropriately influence or bias the content of the paper.

\section{References}

1. New Zealand Companion Animal Council Inc. Companion Animal in New Zealand; New Zealand Companion Animal Council Inc.: Auckland, New Zealand, 2016.

2. Hall, M.J.; Ng, A.; Ursano, R.J.; Holloway, H.; Fullerton, C.; Casper, J. Psychological impact of the animal-human bond in disaster preparedness and response. J. Psychiatr. Pract. 2004, 10, 368-374. [CrossRef] [PubMed]

3. Kurdek, L.A. Pet dogs as attachment figures for adult owners. J. Fam. Psychol. 2009, 23, 439. [CrossRef] [PubMed]

4. Donohue, K.M. Pet loss: Implications for social work practice. Soc. Work 2005, 50, 187-190. [CrossRef] [PubMed]

5. Wrobel, T.A.; Dye, A.L. Grieving pet death: Normative, gender, and attachment issues. OMEGA J. Death Dying 2003, 47, 385-393. [CrossRef] 
6. Zilcha-Mano, S.; Mikulincer, M.; Shaver, P.R. An attachment perspective on human-pet relationships: Conceptualization and assessment of pet attachment orientations. J. Res. Personal. 2011, 45, 345-357. [CrossRef]

7. Chur-Hansen, A. Grief and bereavement issues and the loss of a companion animal: People living with a companion animal, owners of livestock, and animal support workers. Clin. Psychol. 2010, 14, 14-21. [CrossRef]

8. Hunt, M.; Al-Awadi, H.; Johnson, M. Psychological sequelae of pet loss following hurricane Katrina. Anthrozoös 2008, 21, 109-121. [CrossRef]

9. Planchon, L.A.; Templer, D.I.; Stokes, S.; Keller, J. Death of a companion cat or dog and human bereavement: Psychosocial variables. Soc. Anim. 2002, 10, 93-105. [CrossRef]

10. Field, N.P.; Orsini, L.; Gavish, R.; Packman, W. Role of attachment in response to pet loss. Death Stud. 2009, 33, 334-355. [CrossRef] [PubMed]

11. Sharkin, B.S.; Bahrick, A.S. Pet loss: Implications for counselors. J. Couns. Dev. 1990, 68, 306-308. [CrossRef]

12. Panksepp, J. Affective neuroscience and the ancestral sources of human feelings. In Consciousness and Cognition, 1st ed.; Cohen, H., Stemmer, B., Eds.; Elsevier Academic Press: Amsterdam, The Netherlands, 2007.

13. Panksepp, J. The basic emotional circuits of mammalian brains: Do animals have affective lives? Neurosci. Biobehav. Rev. 2011, 35, 1791-1804. [CrossRef] [PubMed]

14. Reefmann, N.; Wechsler, B.; Gygax, L. Behavioural and physiological assessment of positive and negative emotion in sheep. Anim. Behav. 2009, 78, 651-659. [CrossRef]

15. Reimert, I.; Bolhuis, J.E.; Kemp, B.; Rodenburg, T.B. Indicators of positive and negative emotions and emotional contagion in pigs. Physiol. Behav. 2013, 109, 42-50. [CrossRef] [PubMed]

16. Zimmerman, P.; Buijs, S.; Bolhuis, J.; Keeling, L. Behaviour of domestic fowl in anticipation of positive and negative stimuli. Anim. Behav. 2011, 81, 569-577. [CrossRef]

17. Wemelsfelder, F.; Hunter, T.E.; Mendl, M.T.; Lawrence, A.B. Assessing the 'whole animal': A free choice profiling approach. Anim. Behav. 2001, 62, 209-220. [CrossRef]

18. Harding, E.J.; Paul, E.S.; Mendl, M. Animal behaviour: Cognitive bias and affective state. Nature 2004, 427, 312. [CrossRef] [PubMed]

19. Mendl, M.; Burman, O.H.; Parker, R.M.; Paul, E.S. Cognitive bias as an indicator of animal emotion and welfare: Emerging evidence and underlying mechanisms. Appl. Anim. Behav. Sci. 2009, 118, 161-181. [CrossRef]

20. Dawkins, M.S. Through animal eyes: What behaviour tells us. Appl. Anim. Behav. Sci. 2006, 100, 4-10. [CrossRef]

21. Panksepp, J. Feeling the pain of social loss. Science 2003, 302, 237-239. [CrossRef] [PubMed]

22. Newberry, R.C.; Swanson, J.C. Implications of breaking mother-young social bonds. Appl. Anim. Behav. Sci. 2008, 110, 3-23. [CrossRef]

23. Averill, J.R. Grief: Its nature and significance. Psychol. Bull. 1968, 70, 721-748. [CrossRef] [PubMed]

24. Bowlby, J. Grief and mourning in infancy and early childhood. Psychoanal. Study Child 1960, 15, 9-52.

25. Spitz, R.A. Anaclitic depression. Psychoanal. Stud. Child 1946, 2, 313-347. [PubMed]

26. Donaldson, T.M.; Newberry, R.C.; Špinka, M.; Cloutier, S. Effects of early play experience on play behaviour of piglets after weaning. Appl. Anim. Behav. Sci. 2002, 79, 221-231. [CrossRef]

27. Price, E.; Harris, J.; Borgwardt, R.; Sween, M.; Connor, J. Fenceline contact of beef calves with their dams at weaning reduces the negative effects of separation on behavior and growth rate. J. Anim. Sci. 2003, 81, 116-121. [CrossRef] [PubMed]

28. Weary, D.M.; Appleby, M.C.; Fraser, D. Responses of piglets to early separation from the sow. Appl. Anim. Behav. Sci. 1999, 63, 289-300. [CrossRef]

29. Weary, D.M.; Jasper, J.; Hötzel, M.J. Understanding weaning distress. Appl. Anim. Behav. Sci. 2008, 110, $24-41$. [CrossRef]

30. Douglas-Hamilton, I.; Bhalla, S.; Wittemyer, G.; Vollrath, F. Behavioural reactions of elephants towards a dying and deceased matriarch. Appl. Anim. Behav. Sci. 2006, 100, 87-102. [CrossRef]

31. Dudzinski, K.; Sakai, M.; Masaki, K.; Kogi, K.; Hishii, T.; Kurimoto, M. Behavioral observations of adult and sub-adult dolphins towards two dead bottlenose dolphins (one female and one male). Aquat. Mamm. 2003, 29, 108-116. [CrossRef] 
32. Goodall, J. Through a Window: My Thirty Years with the Chimpanzees of Gombe; Houghton Mifflin Harcourt: Boston, MA, USA, 2010.

33. Smuts, B.B. Sex and Friendship in Baboons; Transaction Publishers: Piscataway, NJ, USA, 1985.

34. Payne, K. Sources of social complexity in the three elephant species. In Animal Social Complexity: Intelligence, Culture, and Individualized Societies; de Waal, F.B.M., Tyack, P.L., Eds.; Harvard University Press: Cambridge, MA, USA, 2003.

35. Bates, L.A.; Poole, J.H.; Byrne, R.W. Elephant cognition. Curr. Biol. 2008, 18, R544-R546. [CrossRef] [PubMed]

36. Laudenslager, M.L.; Held, P.; Boccia, M.; Reite, M.; Cohen, J. Behavioral and immunological consequences of brief mother-infant separation: A species comparison. Dev. Psychobiol. 1990, 23, 247-264. [CrossRef] [PubMed]

37. Suomi, S.J.; Harlow, H.F.; Domek, C.J. Effect of repetitive infant-infant separation of young monkeys. J. Abnorm. Psychol. 1970, 76, 161. [CrossRef] [PubMed]

38. Willner, P. The validity of animal models of depression. Psychopharmacology 1984, 83, 1-16. [CrossRef] [PubMed]

39. Hinde, R.; Spencer-Booth, Y.; Bruce, M. Effects of 6-day maternal deprivation on rhesus monkey infants. Nature 1966, 210, 1021-1023. [CrossRef] [PubMed]

40. Seay, B.; Hansen, E.; Harlow, H.F. Mother-infant separation in monkeys. J. Child Psychol. Psychiatr. 1962, 3, 123-132. [CrossRef]

41. Seay, B.; Harlow, H.F. Maternal separation in the rhesus monkey. J. Nerv. Ment. Dis. 1965, 140, $434-441$. [CrossRef] [PubMed]

42. Reite, M.; Kaemingk, K.; Boccia, M.L. Maternal separation in bonnet monkey infants: Altered attachment and social support. Child Dev. 1989, 60, 473-480. [CrossRef] [PubMed]

43. Jensen, G.D.; Tolman, C.W. Mother-infant relationship in the monkey, macaca nemestrina: The effect of brief separation and mother-infant specificity. J. Comp. Physiol. Psychol. 1962, 55, 131-136. [CrossRef] [PubMed]

44. Kaufman, C.I.; Rosenblum, L.A. The reaction to separation in infant monkeys: Anaclitic depression and conservation-withdrawal. Psychosom. Med. 1967, 29, 648-675. [CrossRef] [PubMed]

45. Perkeybile, A.M.; Schiml-Webb, P.A.; O’Brien, E.; Deak, T.; Hennessy, M.B. Anti-inflammatory influences on behavioral, but not cortisol, responses during maternal separation. Psychoneuroendocrinology 2009, 34, 1101-1108. [CrossRef] [PubMed]

46. Murray, L.M.; Byrne, K.; D’Eath, R.B. Pair-bonding and companion recognition in domestic donkeys, equus asinus. Appl. Anim. Behav. Sci. 2013, 143, 67-74. [CrossRef]

47. Ward, C.; Bauer, E.B.; Smuts, B.B. Partner preferences and asymmetries in social play among domestic dog, canis lupus familiaris, littermates. Anim. Behav. 2008, 76, 1187-1199. [CrossRef]

48. Hepper, P.G. Long-term retention of kinship recognition established during infancy in the domestic dog. Behav. Processes 1994, 33, 3-14. [CrossRef]

49. Beerda, B.; Schilder, M.B.; Van Hooff, J.A.; De Vries, H.W.; Mol, J.A. Chronic stress in dogs subjected to social and spatial restriction. I. Behavioral responses. Physiol. Behav. 1999, 66, 233-242. [CrossRef]

50. Guyot, G.W.; Bennett, T.L.; Cross, H.A. The effects of social isolation on the behavior of juvenile domestic cats. Dev. Psychobiol. 1980, 13, 317-329. [CrossRef] [PubMed]

51. Schultz, J.L.; Antender, P.A.; Zawistowski, S. Companion Animal Response to the Loss of an Animal Companion; The American Society for the Prevention of Cruelty to Animals: New York, USA, 1996.

52. Topál, J.; Gácsi, M.; Miklósi, Á.; Virányi, Z.; Kubinyi, E.; Csányi, V. Attachment to humans: A comparative study on hand-reared wolves and differently socialized dog puppies. Anim. Behav. 2005, 70, 1367-1375. [CrossRef]

53. Flannigan, G.; Dodman, N.H. Risk factors and behaviors associated with separation anxiety in dogs. J. Am. Vet. Med. Assoc. 2001, 219, 460-466. [CrossRef] [PubMed]

54. Konok, V.; Dóka, A.; Miklósi, Á. The behavior of the domestic dog (canis familiaris) during separation from and reunion with the owner: A questionnaire and an experimental study. Appl. Anim. Behav. Sci. 2011, 135, 300-308. [CrossRef]

55. Lund, J.D.; Jørgensen, M.C. Behaviour patterns and time course of activity in dogs with separation problems. Appl. Anim. Behav. Sci. 1999, 63, 219-236. [CrossRef] 
56. Mendl, M.; Brooks, J.; Basse, C.; Burman, O.; Paul, E.; Blackwell, E.; Casey, R. Dogs showing separation-related behaviour exhibit a 'pessimistic'cognitive bias. Curr. Biol. 2010, 20, R839-R840. [CrossRef] [PubMed]

57. Borchelt, P.L.; Voith, V.L. Classification of animal behavior problems. Vet. Clin. N. Am. Small Anim. Pract. 1982, 12, 571-585. [CrossRef]

58. Bradshaw, J.; McPherson, J.; Casey, R.; Larter, S. Aetiology of separation-related behaviour in domestic dogs. Vet. Record 2002, 151, 43-46. [CrossRef]

59. Horwitz, D.F. Diagnosis and treatment of canine separation anxiety and the use of clomipramine hydrochloride (clomicalm). J. Am. Anim. Hosp. Assoc. 2000, 36, 107-109. [CrossRef] [PubMed]

60. Wright, J.C.; Nesselrote, M.S. Classification of behavior problems in dogs: Distributions of age, breed, sex and reproductive status. Appl. Anim. Behav. Sci. 1987, 19, 169-178. [CrossRef]

61. Hothersall, D.; Tuber, D. Fears in companion dogs: Characteristics and treatment. In Psychopathology in Animals: Research and Clinical Implications; Academic Press: New York, NY, USA, 1979; pp. 239-255.

62. Schwartz, S. Separation anxiety syndrome in cats: 136 cases (1991-2000). J. Am. Vet. Med. Assoc. 2002, 220, 1028-1033. [CrossRef] [PubMed]

63. Martens, P.; Enders-Slegers, M.J.; Walker, J.K. The emotional lives of companion animals: Attachment and subjective claims by owners of cats and dogs. Anthrozoös 2016, 29, 73-88. [CrossRef]

64. Meagher, R.K. Observer ratings: Validity and value as a tool for animal welfare research. Appl. Anim. Behav. Sci. 2009, 119, 1-14. [CrossRef]

65. Dodd, P.; Dowling, S.; Hollins, S. A review of the emotional, psychiatric and behavioural responses to bereavement in people with intellectual disabilities. J. Intellect. Dis. Res. 2005, 49, 537-543. [CrossRef] [PubMed]

66. Brickell, C.; Munir, K. Grief and its complications in individuals with intellectual disability. Harv. Rev. Psychiatr. 2008, 16, 1-12. [CrossRef] [PubMed]

67. Bennett, P.C.; Rohlf, V.I. Owner-companion dog interactions: Relationships between demographic variables, potentially problematic behaviours, training engagement and shared activities. Appl. Anim. Behav. Sci. 2007, 102, 65-84. [CrossRef]

68. Blackwell, E.J.; Twells, C.; Seawright, A.; Casey, R.A. The relationship between training methods and the occurrence of behavior problems, as reported by owners, in a population of domestic dogs. J. Vet. Behav. Clin. Appl. Res. 2008, 3, 207-217. [CrossRef]

69. Arhant, C.; Bubna-Littitz, H.; Bartels, A.; Futschik, A.; Troxler, J. Behaviour of smaller and larger dogs: Effects of training methods, inconsistency of owner behaviour and level of engagement in activities with the dog. Appl. Anim. Behav. Sci. 2010, 123, 131-142. [CrossRef]

70. Mariti, C.; Papi, F.; Mengoli, M.; Moretti, G.; Martelli, F.; Gazzano, A. Improvement in children's humaneness toward nonhuman animals through a project of educational anthrozoology. J. Vet. Behav. Clin. Appl. Res. 2011, 6, 12-20. [CrossRef]

71. Morris, P.H.; Doe, C.; Godsell, E. Secondary emotions in non-primate species? Behavioural reports and subjective claims by animal owners. Cogn. Emot. 2008, 22, 3-20. [CrossRef]

72. Mariti, C.; Gazzano, A.; Moore, J.L.; Baragli, P.; Chelli, L.; Sighieri, C. Perception of dogs' stress by their owners. J. Vet. Behav. Clin. Appl. Res. 2012, 7, 213-219. [CrossRef]

73. Appleby, D.; Pluijmakers, J. Separation anxiety in dogs: The function of homeostasis in its development and treatment. Vet. Clin. N. Am. Small Anim. Pract. 2003, 33, 321-344. [CrossRef]

74. Boissy, A.; Le Neindre, P. Behavioral, cardiac and cortisol responses to brief peer separation and reunion in cattle. Physiol. Behav. 1997, 61, 693-699. [CrossRef]

75. Watts, J.M.; Stookey, J.M.; Schmutz, S.M.; Waltz, C.S. Variability in vocal and behavioural responses to visual isolation between full-sibling families of beef calves. Appl. Anim. Behav. Sci. 2001, 70, 255-273. [CrossRef]

76. Rault, J.-L.; Boissy, A.; Boivin, X. Separation distress in artificially-reared lambs depends on human presence and the number of conspecifics. Appl. Anim. Behav. Sci. 2011, 132, 42-50. [CrossRef]

77. Lidfors, L.M. Behavioural effects of separating the dairy calf immediately or 4 days post-partum. Appl. Anim. Behav. Sci. 1996, 49, 269-283. [CrossRef]

78. Rushen, J.; Boissy, A.; Terlouw, E.; De Passille, A. Opioid peptides and behavioral and physiological responses of dairy cows to social isolation in unfamiliar surroundings. J. Anim. Sci. 1999, 77, 2918-2924. [CrossRef] [PubMed] 
79. Lansade, L.; Bouissou, M.-F.; Erhard, H.W. Reactivity to isolation and association with conspecifics: A temperament trait stable across time and situations. Appl. Anim. Behav. Sci. 2008, 109, 355-373. [CrossRef]

80. Carbonaro, D.; Friend, T.; Dellmeier, G.; Nuti, L. Behavioral and physiological responses of dairy goats to isolation. Physiol. Behav. 1992, 51, 297-301. [CrossRef]

81. Bradshaw, G.A.; Schore, A.N.; Brown, J.L.; Poole, J.H.; Moss, C.J. Elephant breakdown. Nature 2005, $433,807$. [CrossRef] [PubMed]

82. Pryor, P.A.; Hart, B.L.; Cliff, K.D.; Bain, M.J. Effects of a selective serotonin reuptake inhibitor on urine spraying behavior in cats. J. Am. Vet. Med. Assoc. 2001, 219, 1557-1561. [CrossRef] [PubMed]

83. Turner, D.C. The Domestic Cat: The Biology of Its Behaviour; Cambridge University Press: Cambridge, UK, 2000.

84. Brown, A.E. Grief in the chimpanzee. Am. Nat. 1879, 13, 173-175. [CrossRef]

85. McComb, K.; Baker, L.; Moss, C. African elephants show high levels of interest in the skulls and ivory of their own species. Biol. Lett. 2006, 2, 26-28. [CrossRef] [PubMed]

86. Sugiyama, Y.; Kurita, H.; Matsui, T.; Kimoto, S.; Shimomura, T. Carrying of dead infants by japanese macaque (Macaca fuscata) mothers. Anthropol. Sci. 2009, 117, 113-119. [CrossRef]

87. Biro, D.; Humle, T.; Koops, K.; Sousa, C.; Hayashi, M.; Matsuzawa, T. Chimpanzee mothers at bossou, guinea carry the mummified remains of their dead infants. Curr. Biol. 2010, 20, R351-R352. [CrossRef] [PubMed]

88. Cronin, K.A.; Van Leeuwen, E.J.; Mulenga, I.C.; Bodamer, M.D. Behavioral response of a chimpanzee mother toward her dead infant. Am. J. Primatol. 2011, 73, 415-421. [CrossRef] [PubMed]

89. Albert, A.; Bulcroft, K. Pets and urban life. Anthrozoös 1987, 1, 9-25. [CrossRef]

90. Bahlig-Pieren, Z.; Turner, D.C. Anthropomorphic interpretations and ethological descriptions of dog and cat behavior by lay people. Anthrozoös 1999, 12, 205-210. [CrossRef]

91. Fidler, M.; Light, P.; Costall, A. Describing dog behavior psychologically: Pet owners versus non-owners. Anthrozoös 1996, 9, 196-200. [CrossRef]

92. Serpell, J.A. Anthropomorphism and anthropomorphic selection-beyond the "cute response". Soc. Anim. 2002, 10, 437-454. [CrossRef]

93. Fox, R. Animal behaviours, post-human lives: Everyday negotiations of the animal-human divide in pet-keeping. Soc. Cult. Geogr. 2006, 7, 525-537. [CrossRef]

94. Morris, P.; Knight, S.; Lesley, S. Belief in animal mind: Does familiarity with animals influence beliefs about animal emotions? Soc. Anim. 2012, 20, 211-224. [CrossRef]

(C) 2016 by the authors; licensee MDPI, Basel, Switzerland. This article is an open access article distributed under the terms and conditions of the Creative Commons Attribution (CC-BY) license (http:/ / creativecommons.org/licenses/by/4.0/). 